Revista Eletrônica de Direito Processual - REDP.

Rio de Janeiro. Ano 13. Volume 20. Número 2. Maio a Agosto de 2019

Periódico Quadrimestral da Pós-Graduação Stricto Sensu em Direito Processual da UERJ

Patrono: José Carlos Barbosa Moreira (in mem.). ISSN 1982-7636. pp. 245-266

www.redp.uerj.br

\title{
MULTIDISTRICT LITIGATION E COLETIVIZAÇÃO PARCIAL: \\ UMA REAL OPÇÃO AO MODELO DE AÇÕES DE CLASSE? ${ }^{1}$
}

\section{MULTIDISTRICT LITIGATION AND AGGREGATION MECHANISMS: A REAL ALTERNATIVE TO THE CLASS ACTION RULE?}

Gustavo Osna

Professor Adjunto dos Programas de Graduação e de PósGraduação stricto sensu em Direito da PUC/RS. Doutor em Direito das Relações Sociais pela UFPR. Mestre em Direito das Relações Sociais e Bacharel em Direito pela UFPR. Membro do Instituto Brasileiro de Direito Processual. Advogado. Curitiba/PR. E-mail: gustavo@mosadvocacia.com.br

RESUMO: Recentemente, tornou-se recorrente defender que técnicas de agregação de direitos, como o multidistrict litigation, poderiam representar uma alternativa viável para as ações de classe. O presente artigo procura analisar a adequação entre o discurso teórico e a realidade material desse mecanismo, avaliando se, verdadeiramente, seu uso pode constituir uma via hígida para o processo coletivo. Nesse sentido, nota-se que, se o multidistrict litigation tem uma estrutura normativa bastante diversa das class actions, sua efetivação costuma caminhar em sentido contrário. Como consequência, a coletivização parcial por ela proposta não parece, realmente, se verificar.

PAlavRas CHAVE: Processo Coletivo, Ações de Classe, Multidistrict Litigation, Coletivização.

\footnotetext{
${ }^{1}$ Artigo recebido em 26/02/2019 e aprovado em 04/08/2019.
} 
Revista Eletrônica de Direito Processual - REDP.

Rio de Janeiro. Ano 13. Volume 20. Número 2. Maio a Agosto de 2019

Periódico Quadrimestral da Pós-Graduação Stricto Sensu em Direito Processual da UERJ

Patrono: José Carlos Barbosa Moreira (in mem.). ISSN 1982-7636. pp. 245-266

www.redp.uerj.br

ABSTRACT: Recently, the argument that aggregation mechanisms, as the multidistrict litigation, could be an alternative to class actions became usual. This essay analyses the compatibility between the theoretical frame and the material enforcement of such tool, observing if its use can truly be an adequate path to complex litigation. In this sense, it is presented that, if the multidistrict litigation has a legislative base quite diverse from the class actions one, its reality regularly goes on the opposite way. As a consequence, the kind of partial aggregation that the technique could offer is not really achieved.

KEYWORDS: Collective Litigation, Class Actions, Multidistrict Litigation, Aggregation.

\section{Introdução}

Não há dúvidas de que, ao longo dos últimos anos, o tema da tutela coletiva assumiu especial importância em nosso sistema processual. A questão possui importante respaldo normativo, substanciado, especialmente, na Lei de Ação Civil Pública e em seu posterior complemento pelo Código de Defesa do Consumidor. Além disso, também é certo que doutrina e Tribunais procuraram se inserir nessa quadra, dedicando olhares atentos a diferentes tópicos ligados à tutela coletiva ${ }^{2}$.

Nessa jornada, não se tornou incomum o recurso à análise comparada. A questão não surpreende, tampouco se mostra imotivada. Afinal, ao mesmo tempo em que é sabido que o processo coletivo está longe de ser uma exclusividade de nosso ordenamento, é também corriqueira a constatação de que o exame comparatista (desde que provido das necessárias cautelas) pode desempenhar uma relevante função na melhor composição do Direito ${ }^{3}$.

É com esse propósito que, em tempos recentes, tem se tornado mais comum a indicação de que uma técnica específica do modelo processual estadunidense - que ali viria alegadamente atuando em substituição às class actions - poderia também aqui desempenhar um importante papel. Trata-se do mecanismo da multidistrict litigation. Diante da

\footnotetext{
${ }^{2}$ Apreciamos a questão com cautela em ARENHART, Sérgio Cruz. OSNA, Gustavo Curso de Processo Civil Coletivo. São Paulo: Ed. RT, 2019.

${ }^{3}$ Ver, nesse particular, MENDES, Aluisio Gonçalves de Castro. Ações coletivas no direito comparado e nacional. 2. ed. São Paulo: Ed. RT, 2009.
} 
Revista Eletrônica de Direito Processual - REDP.

Rio de Janeiro. Ano 13. Volume 20. Número 2. Maio a Agosto de 2019

Periódico Quadrimestral da Pós-Graduação Stricto Sensu em Direito Processual da UERJ

Patrono: José Carlos Barbosa Moreira (in mem.). ISSN 1982-7636. pp. 245-266

www.redp.uerj.br

possibilidade aberta, considera-se necessário realizar uma avaliação criteriosa de tal mecanismo - investigando-se tanto aquilo a que ele teoricamente se presta quanto o papel que materialmente desempenha. Somente assim o ajuste nos parece viável, aferindo se esse "novo" caminho para o processo coletivo deve realmente receber primazia.

Por qual motivo o sistema de multidistrit litigation foi originalmente concebido? Que tipo de propósito influenciou sua composição normativa? A técnica, verdadeiramente, tem representado uma alternativa às class actions? A sua operacionalização é plenamente condizente com seus objetivos iniciais?

O presente artigo procura analisar, de maneira sucinta, cada uma dessas indagações. A partir delas, pretende-se contribuir para a devida compreensão da ferramenta em questão e de suas potencialidades, verificando-se, com viés crítico, o papel que ela pode ou não desempenhar em nosso arcabouço de tutela coletiva.

\section{A Tutela Coletiva, as Class Actions e o Multidistrict Litigation}

Para atingir o objetivo proposto, então, há um suporte cuja investigação se torna necessária, firmando as premissas e as balizas imprescindíveis à orientação do estudo. Tratase das construções teóricas que conferem sentido à ideia de tutela coletiva, assim como da avaliação do papel desempenhado nesse campo pela ferramenta do multidistrict litigation. O presente capítulo se presta à realização dessa análise, investigando os pilares conceituais básicos para o ensaio e demonstrando a ampliação funcional da técnica em questão na realidade estadunidense. Somente dessa maneira se pode, posteriormente, avaliar sua efetividade como alternativa às ações de classe.

\subsection{Coletivização e Ação Coletiva}

Tendo em vista as considerações trazidas acima, parece haver uma questão prévia a ser elucidada para permitir maior clareza ao atual ensaio. É que, como sinalizado, seu conteúdo se insere na esfera específica da tutela coletiva - ou, mais precisamente, no campo da proteção aglutinada de interesses individuais. Como consequência, é relevante traçar algumas breves considerações ligadas a esse ponto, facilitando sua compreensão. 
Revista Eletrônica de Direito Processual - REDP.

Rio de Janeiro. Ano 13. Volume 20. Número 2. Maio a Agosto de 2019

Periódico Quadrimestral da Pós-Graduação Stricto Sensu em Direito Processual da UERJ

Patrono: José Carlos Barbosa Moreira (in mem.). ISSN 1982-7636. pp. 245-266

www.redp.uerj.br

Com esse propósito, podemos dizer de um modo geral que a tutela coletiva de

direitos constitui uma das duas grandes facetas do processo coletivo. Nela, não se procura proteger interesses essencialmente metaindividuais (de natureza difusa ou coletiva), mas sim oferecer uma nova via procedimental para a proteção de interesses tipicamente individuais ${ }^{4}$. Embora tais direitos teoricamente pudessem ser protegidos por meio do processo civil tradicional, considera-se que a porta coletiva pode representar um caminho mais adequado - por diferentes motivos.

Para compreender o problema, o recurso à via exemplificativa se mostra extremamente valioso e didático. Nesse sentido, suponhamos que a instituição financeira Gama, ao longo do ano de 2018, realiza cobranças mensais abusivas de todos os seus correntistas - fazendo-as constar, em fatura, como "taxa de manutenção de número de agência". Imaginemos que, gradualmente, começa-se a colocar em dúvida a legalidade de referidas cobranças, levando diferentes consumidores a pleitear em juízo a reparação em face da sociedade.

Nessa hipótese, haveria algum óbice teórico para que cada um dos lesados pela conduta de Gama litigasse de maneira pulverizada e individual? Será necessária alguma autorização específica para esse fim? Diversamente, os interesses titularizados pelos consumidores, isoladamente considerados, seriam compatíveis com a própria noção elementar de "direito subjetivo"?

Enfrentando uma a uma as questões, observa-se que suas respostas sequer são desafiadoras. Logicamente, no exato instante em que a instituição financeira ocasionasse um prejuízo patrimonial e individual a algum de seus correntistas (como é o caso da referida taxa) estaria oportunizado o seu exercício da garantia processual de ação. O desenho se confunde com o próprio esquema mais clássico do processo civil, não causando qualquer tipo de incompreensão.

Ainda assim, porém, algumas dúvidas poderiam surgir. Caso cada um dos correntistas manejasse sua pretensão em caráter individual, não seria crível que, por mais que a cobrança fosse idêntica, fossem oferecidas diferentes respostas em juízo? Como exemplo, não seria viável que julgadores diversos pudessem concluir pela licitude do ato,

\footnotetext{
${ }^{4}$ Ver, aqui, passim, OSNA, Gustavo. Direitos individuais homogêneos: pressupostos, fundamentos e aplicação no processo civil. São Paulo: Ed. RT, 2014. Também, ARENHART, Sérgio Cruz. OSNA, Gustavo. Ob. cit. p.75 e ss.
} 
Revista Eletrônica de Direito Processual - REDP.

Rio de Janeiro. Ano 13. Volume 20. Número 2. Maio a Agosto de 2019

Periódico Quadrimestral da Pós-Graduação Stricto Sensu em Direito Processual da UERJ

Patrono: José Carlos Barbosa Moreira (in mem.). ISSN 1982-7636. pp. 245-266

www.redp.uerj.br

pela sua ilicitude apta a gerar direito à repetição em dobro ou pela sua ilicitude capaz de autorizar, apenas, repetição de maneira simples? Nesse caso, haveria uma verdadeira tutela à igualdade e à impessoalidade?

As indagações não param por aí. Considerando a escassez de recursos inerente ao setor público, seria razoável que o Poder Judiciário dispendesse esforços reiterados e isolados para solucionar repetidamente a mesma questão? Essa postura seria aquela mais compatível com as atuais necessidades de nossa Administração? Mais que isso, ela seria realmente aceitável, diante da previsão constitucional da eficiência administrativa?

A esse tipo de provocação, poderiam se somar ainda aspectos afeitos ao acesso à justiça, aos efeitos dissuasivos da jurisdição ou à sua estabilidade. Em qualquer dos casos, o que se veria é que, embora a estrutura tradicional do processo teoricamente pudesse dar conta de situações como aquela envolvendo a sociedade Gama, há inúmeros obstáculos que decorrem dessa opção; por mais que o tratamento individual e pulverizado fosse possível, seu uso não ocorreria sem graves externalidades negativas ${ }^{5}$. E é por força disso que diferentes ordenamentos passaram a construir alternativas voltadas a aglutinar tais interesses; a coletivizá-los por meio do processo, viabilizando que, embora individuais, fossem acertados de maneira conjunta.

\subsection{O "Sucesso" e a Resistência às Class Actions}

Foi visto no tópico anterior que, nas oscilações históricas do processo civil, entrou em cena ao longo do último século a percepção de que seria pertinente criar portas coletivas para a proteção de interesses individuais. Em que pese sua apreciação pulverizada fosse teoricamente factível, haveria diferentes motivos, ligados à melhoria da prestação jurisdicional, que justificariam esse novo encaminho e a sua valorização.

Avaliando esse ponto, podemos estabelecer que uma primeira e intuitiva via por meio da qual esse movimento de coletivização se materializaria seria a própria formação de ações coletivas. Em poucas palavras, procura-se, por essa trilha, garantir que todos os interesses individuais ligados à classe sejam protegidos por meio de uma única ação. Insere-

\footnotetext{
${ }^{5}$ Idem. ibidem.
} 
Revista Eletrônica de Direito Processual - REDP.

Rio de Janeiro. Ano 13. Volume 20. Número 2. Maio a Agosto de 2019

Periódico Quadrimestral da Pós-Graduação Stricto Sensu em Direito Processual da UERJ

Patrono: José Carlos Barbosa Moreira (in mem.). ISSN 1982-7636. pp. 245-266

www.redp.uerj.br

se aqui, de forma emblemática, a técnica de class actions prevista no direito estadunidense pela Federal Rule 23 - pertinente para o presente ensaio e provida de proeminência teórica ao longo das últimas décadas ${ }^{6}$.

De fato, conforme já destacado em nossa doutrina ${ }^{7}$, é certo que as US class actions se enquadram na noção de ação coletiva acima indicada. É esse o propósito que norteia a sua tramitação. Em resumo, a medida possui como origem a propositura de uma demanda originalmente individual, em cujo bojo se requeira a certificação coletiva. Essa conversão se sujeitaria ao preenchimento tanto de requisitos gerais quanto de pressupostos específicos. Os primeiros, previstos na Rule 23(a) como "pré-requisitos", passariam por tópicos como a numerosidade, a comunhão de interesses (commonality) e a representação adequada ${ }^{8}$. Já as condições específicas, trazidas pela Rule 23(b) ${ }^{9}$, revelariam a impossibilidade de que se fale em uma única espécie de class action, havendo diferentes estruturas procedimentais compatíveis com a figura - como notado por Issacharoff ${ }^{10}$.

\footnotetext{
${ }^{6}$ Sobre o avanço do mecanismo, ver HENSLER, Deborah. Class Action Dilemmas - Pursuing public goals for private gain. Santa Monica: Rand, 2000. p.10-11

${ }^{7}$ Ver, exemplificativamente, GIDI, Antonio. A Class Action como instrumento de tutela coletiva de direitos. São Paulo: Ed. RT, 2007. ROQUE, André Vasconcelos. Class Action - Ações Coletivas nos Estados Unidos: o que podemos aprender com eles?. Salvador: Editora JusPodivm, 2013. CRUZ E TUCCI, José Rogério. Class action e mandado de segurança coletivo, diversificações conceptuais. São Paulo: Ed. RT, 1990.

8 "(a) Prerequisites. One or more members of a class may sue or be sued as representative parties on behalf of all members only if: (1) the class is so numerous that joinder of all members is impracticable; (2) there are questions of law or fact common to the class; (3) the claims or defenses of the representative parties are typical of the claims or defenses of the class; and (4) the representative parties will fairly and adequately protect the interests of the class".

9 "(b) A class action may be maintained if Rule 23(a) is satisfied and if: (1) prosecuting separate actions by or against individual class members would create a risk of: (A) inconsistent or varying adjudications with respect to individual class members that would establish incompatible standards of conduct for the party opposing the class; or (B) adjudications with respect to individual class members that, as a practical matter, would be dispositive of the interests of the other members not parties to the individual adjudications or would substantially impair or impede their ability to protect their interests; (2) the party opposing the class has acted or refused to act on grounds that apply generally to the class, so that final injunctive relief or corresponding declaratory relief is appropriate respecting the class as a whole; or (3) the court finds that the questions of law or fact common to class members predominate over any questions affecting only individual members, and that a class action is superior to other available methods for fairly and efficiently adjudicating the controversy. The matters pertinent to these findings include: (A) the class members' interests in individually controlling the prosecution or defense of separate actions; $(B)$ the extent and nature of any litigation concerning the controversy already begun by or against class members; $(C)$ the desirability or undesirability of concentrating the litigation of the claims in the particular forum; and $(D)$ the likely difficulties in managing a class action." 10 "As the name would imply, the Rule 23 (a) prerequisites for class certification are just that: prerequisites. Rule $23(b)$ then requires that a court finding that the prerequisites are met determine which of the three primary sorts of class action is to be created. The distinct class action types correspond to familiar problems in the joinder rules, responding to competing demands for insufficient resources, the indivisibility of the remedies sought by the class, or the simple efficiency commands of aggregate treatment of small claims that would not merit prosecution on their own". ISSACHAROFF, Samuel. Civil Procedure. New York: Foundation Press, 2005. p.79.
} 
Revista Eletrônica de Direito Processual - REDP.

Rio de Janeiro. Ano 13. Volume 20. Número 2. Maio a Agosto de 2019

Periódico Quadrimestral da Pós-Graduação Stricto Sensu em Direito Processual da UERJ

Patrono: José Carlos Barbosa Moreira (in mem.). ISSN 1982-7636. pp. 245-266

www.redp.uerj.br

De todo modo, na base dessa ação de classe estaria a tentativa de reunir, em um mesmo processo, os interesses serialmente titularizados pelos membros do grupo. Em outros termos, a possibilidade de agregá-los em um só litígio. No exemplo trazido no tópico anterior, ligado à sociedade Gama, passar-se-ia então a admitir que, em um único processo, fossem trazidos à mesa os interesses de todos os membros do grupo. Se foi visto que a pulverização e o debate atomizado poderiam trazer prejuízos para a prestação jurisdicional, adota-se um caminho radical voltado a atenuar esses malefícios.

De qualquer sorte, é certo que, embora as class actions tenham atingido um acentuado "sucesso" material e acadêmico ${ }^{11}$, o arsenal de críticas voltadas à sua direção sempre foi considerável. De uma forma geral, o principal elemento trazido nesse contexto foi a possível incompatibilidade entre a ação coletiva e a noção de devido processo. E isso porque, inevitavelmente, a coletivização de direitos traria consigo alguma forma de redução da possibilidade de participação individual em juízo - apostando as suas fichas em uma vinculação por representação ${ }^{12}$.

Nesse cenário, o cerne do problema se encontra no contínuo conflito existente entre a tutela coletiva de direitos individuais e a defesa de uma mentalidade individualista para o processo ${ }^{13}$. É a partir desse atrito que se pode conferir maior ou menor apego a uma visão liberal dos elementos processuais, determinando os aspectos procedimentais inerentes à coletivização e, com isso, ditando os contornos de sua efetividade. Essa situação se tornou visível no âmbito das class action, gerando duas formas diversas de conceber a ferramenta e os seus contornos, como identificado por Lahav ${ }^{14}$.

De um lado, há teóricos que encampam expressa ou implicitamente uma leitura mais individualista do processo, para, a partir dela, extrair discursos que almejam restringir

\footnotetext{
${ }^{11}$ Devo a Oscar G. Chase o alerta quanto à necessidade de que, ao falar-se no "sucesso" do mecanismo, utilizese tonalidade suave e ponderada. Isso porque, sem óbice de seu uso recorrente, não são poucas as ressalvas trazidas pela doutrina e pelos tribunais à sua utilização.

12 Assim, VITORELLI, Edilson. O devido processo legal coletivo: dos direitos aos litígios coletivos. São Paulo: Ed. RT, 2016. Também, ARENHART, Sérgio Cruz. OSNA, Gustavo. Ob. cit. p.196 e ss.

${ }^{13}$ Nesse sentido, passim, OSNA, Gustavo. Direitos individuais homogêneos.

14 "There are two dominant views of the class action's structure and two dominant views of the class action lawyer. Some see the class action as an aggregation of individuals, a complex joinder device and nothing more. Others view the class action as transforming the class members into an entity. Similarly, there are two dominant views of the class action lawyer. Many see the class action lawyer as an entrepreneur, seeking out litigation and personally benefitting from gains accruing to class members. Others view the class action lawyer as a public servant or a "private attorney general," privately vindicating rights through lawsuits that public officials do not have the resources to pursue". Cita-se, LAHAV, Alexandra D. Two Views of Class Action. In. Fordham Law Review. n.79. New York: Fordham University, 2011. p.1939.
} 
Revista Eletrônica de Direito Processual - REDP.

Rio de Janeiro. Ano 13. Volume 20. Número 2. Maio a Agosto de 2019

Periódico Quadrimestral da Pós-Graduação Stricto Sensu em Direito Processual da UERJ

Patrono: José Carlos Barbosa Moreira (in mem.). ISSN 1982-7636. pp. 245-266

www.redp.uerj.br

a extensão da ação de classe e a sua abrangência procedimental. Essa leitura pode ser vista

na obra de Martin Redish, fundamentando sua chamada aggregation view a respeito do instituto. Com efeito, por conceber que o individualismo estaria no centro do direito processual civil estadunidense e que no conflito com a coletivização deveria ser protegido ${ }^{15}$, o autor chega a conclusões como a crítica à lógica de opt out ${ }^{16}$. Em síntese, seria necessário preservar a autonomia dos indivíduos, razão pela qual a tutela coletiva de direitos individuais não poderia desconsiderar esse aspecto.

De outro lado, há autores que se colocam na mão oposta diante do conflito entre a coletivização de interesses e o individualismo processual, acreditando que os benefícios trazidos pela ação de classe justificariam que esse último cedesse. É assim, por exemplo, com David Shapiro, fundamentando sua célebre visão da "classe como cliente" (entity view) e conferindo à class action ditames procedimentais nos quais os valores liberais clássicos não poderiam se manter intactos ${ }^{17}$.

Sob essa lógica, ainda que os interesses coletivizados em momento algum deixassem de apresentar titularidade individual ${ }^{18}$, seria preciso reler a autonomia disponibilizada aos sujeitos em seu exercício. Haveria espaço para uma valorização da tutela coletiva em detrimento da preservação dos parâmetros tradicionais, impactando em aspectos como a restrição da possibilidade de autoexclusão ${ }^{19}$. De qualquer modo, porém, a questão

\footnotetext{
${ }^{15}$ Delineando sua perspectiva da class action como mecanismo de agregação de direitos, o autor enfatiza que as teorias divergentes "ignore or reject core notions of liberal individualism which, I believe, underlie American liberal democracy in general and our adversary system of litigation" (p.88), constatando que "there are, to be sure, potential tensions between the class action procedure and the political theory of process-based individualism. In situations where this tension is inescapable, the dominant normative force of process-based individualism requires that the class action procedure be justified by a showing of a truly compelling justification". (p.125). REDISH, Martin. Wholesale Justice - Constitutional Democracy and the Problem of the Class Action Lawsuit. Stanford: Stanford University Press, 2009.

${ }^{16}$ Em seu entendimento, uma estrutura desta natureza "has the effect of putting words into a litigant's moutha practice that contradicts fundamental percepts of liberal theory". Não obstante, deve-se ver que mesmo o autor, sem se descurar do caráter funcional da coletivização (como comumente acontece em nossa doutrina), enfatiza que em hipóteses como a das small claim class action a estrutura de opt out poderia se mostrar superior, por ser pouco concreta a presunção de que os indivíduos teriam um interesse vultoso em manter o "controle" sobre seus litígios. Idem. p.131-135.

${ }^{17}$ Assim, SHAPIRO, David L. Class Actions: The Class as Party and Client. In. Notre Dame Law Review. vol.73. Notre Dame: University of Notre Dame, 1998.

${ }^{18}$ Com efeito, Shapiro salienta, por exemplo, que "even this entity model does not deny the class member the opportunity to seek private advice, or to contribute in some way to the progress of the litigation". Em sua visão, de fato, não há qualquer forma de negativa de que a class action agrega direitos individuais, mas apenas uma limitação à autonomia individual em juízo. Idem

${ }^{19} \mathrm{O}$ teórico destaca que "the individual who is a member of the class, for whatever purpose, is and must remain a member of the class, and as a result must tie his fortunes to those group with respect to the litigation, its process and its outcome". Idem. p.919.
} 
Revista Eletrônica de Direito Processual - REDP.

Rio de Janeiro. Ano 13. Volume 20. Número 2. Maio a Agosto de 2019

Periódico Quadrimestral da Pós-Graduação Stricto Sensu em Direito Processual da UERJ

Patrono: José Carlos Barbosa Moreira (in mem.). ISSN 1982-7636. pp. 245-266

www.redp.uerj.br

segue possuindo acentuada controvérsia - o que, em alguns casos, pode levar a uma minoração da própria utilidade da técnica.

\subsection{O Multidistrict Litigation e sua Expansão}

Viu-se acima que o instrumento da class actions, historicamente, assumiu papel de destaque na esfera processual estadunidense. Mais que isso, tornou-se recorrente identificá-lo como verdadeiro exemplo global de mecanismo de tutela coletiva, dados os benefícios que o rito (por meio de sua rigorosa coletivização total) poderia alcançar.

Não obstante, foi igualmente destacado que o sacrifico à participação individual, inevitavelmente ocasionado pela ação coletiva, despertou ressalvas e críticas ligadas à Federal Rule 23. Em grande medida, foi precisamente por força dessas ponderações que o mecanismo de multidistrict litigation, também previsto no sistema processual estadunidense, passou a desempenhar um papel de maior destaque do que previamente imaginado.

Para compreender esse problema, é importante notar que a class action não foi o único mecanismo de processo coletivo desenvolvido em perspectiva comparada - por mais que tenha sido aquele que atingiu maior protagonismo. Alternativamente, forjaram-se outras vias procedimentais que, mesmo que em menor escala, procuraram conferir tratamento coletivo a questões individuais - ora para julgá-las coletivamente, ora para permitir a resolução conjunta de algo que lhes é comum. Mesmo sem formar uma ação de classe, esses artifícios também nos parecem condizentes com a ideia de processo coletivo.

Esclarecendo esse ponto, vale novamente lembrar o exemplo, já referido no presente artigo, ligado à cobrança reiterada de uma tarifa pela instituição financeira Gama. E isso porque nessa circunstância, a formação de uma medida tipicamente coletiva seria apenas uma das formas de coletivização teoricamente admissíveis. Com um viés mais parcial, seria possível, por exemplo, que diante de múltiplas demandas individuais relacionadas à cobrança se optasse por resolver incidental e coletivamente apenas a questão comum, tornando-a vinculante. Haveria espaço, também, para que se procedesse a uma efetiva reunião de todos os processos perante um mesmo juízo, com vistas a facilitar a instrução probatória. Em todos os casos, seria dado algum passo no sentido da aglutinação de questões individuais. . 
Revista Eletrônica de Direito Processual - REDP.

Rio de Janeiro. Ano 13. Volume 20. Número 2. Maio a Agosto de 2019

Periódico Quadrimestral da Pós-Graduação Stricto Sensu em Direito Processual da UERJ

Patrono: José Carlos Barbosa Moreira (in mem.). ISSN 1982-7636. pp. 245-266

www.redp.uerj.br

Esse tipo de ideia possui como exemplo relevante o mecanismo alemão das

Musterverfahren. A ferramenta, já analisada com maior ênfase por nossa doutrina ${ }^{20}$, prestase exatamente a esse tipo de aglutinação parcial de interesses - permitindo que as demandas individuais tenham seu curso autonomamente, mas as paralisando para a resolução conjunta de sua questão comum ${ }^{21}$. Mais que isso, sua estrutura geral serviu de inspiração para a adoção, pelo nosso Código de Processo Civil, de um incidente de resolução de demandas repetitivas.

Do mesmo modo, essa mentalidade também é vista no modelo inglês de Group Litigation Order. Assim como ocorre com a lógica alemã, igualmente nessa estrutura a ideologia central é a possibilidade (e a potencial efetividade) de que questões comuns sejam tratadas de forma conjunta, bloqueando-se eventuais riscos da pulverização em favor de uma administração mais gerencial ${ }^{22}$. Essa vocação reflete na própria maleabilidade que permeia o instituto, admitindo-se seu uso em diferentes ocasiões e a partir de circunstâncias procedimentais também diversas ${ }^{23}$.

\footnotetext{
${ }^{20}$ Ver, por todos, CABRAL, Antonio do Passo. O novo procedimento-modelo (Musterverfahren) alemão: uma alternativa às ações coletivas. In. Revista de Processo. v.147. São Paulo: Ed.RT, 2007.

21 "O escopo do Procedimento-Modelo é estabelecer uma esfera de decisão coletiva de questões comuns a litígios individuais, sem esbarrar nos ataques teóricos e entraves práticos da disciplina das ações coletivas de tipo representativo. Objetiva-se o esclarecimento unitário de características típicas a várias demandas isomórficas, com um espectro de abrangência subjetivo para além das partes. A finalidade do procedimento é fixar posicionamento sobre supostos fáticos ou jurídicos de pretensões repetitivas. A lei é clara em apontar estes escopos (Feststellungsziele) expressamente, assinalando que devem inclusive ser indicados no requerimento inicial ( $\$ 1$ (2)). Assim, não é difícil identificar o objeto do incidente coletivo: no Musterverfahren decidem-se apenas alguns pontos litigiosos (Streitpunkte) expressamente indicados pelo requerente (apontados concretamente) e fixados pelo juízo, fazendo com que a decisão tomada em relação a estas questões atinja vários litígios individuais. Pode-se dizer, portanto, que o mérito da cognição no incidente compreende elementos fáticos ou questões prévias (Varfragen) de uma relação jurídica ou de fundamentos da pretensão individual". Idem. p.132.

${ }^{22}$ Referindo-se ao mecanismo, Neil Andrews destaca que "esse tipo de ordem é a mola mestra do sistema inglês quanto ao tratamento dado aos litígios com múltiplas partes (...) as GLO - Group Litigation Orders são uma forma específica de reunião das partes, por meio de listagem de ações com registro em grupo. Seus principais componentes são: (i) o tribunal deve aprovar a ordem do litígio em grupo; (ii) ao contrário do modelo de representação (...), o litígio em grupo envolve o opt in de cada indivíduo; (iii) um membro do grupo é titular tanto de uma cota do grupo, quanto do status geral de parte, no sentido pleno da expressão, do processo; (iv) durante o trâmite das GLO, o tribunal exerce administração intensa do caso e da instrução; (v) as decisões sobre questões "comuns" atingem o grupo, sendo a seu favor; (vi) os membros do grupo compartilham a responsabilidade pelas custas que decorrerem das questões "comuns"”. ANDREWS, Neil. O Moderno Processo Civil. Trad. Teresa Arruda Alvim Wambier. São Paulo: Ed. RT, 2009. p.343.

23 "Trata-se de instrumento muito mais flexível e que admite a possibilidade de oferecer-se soluções diferentes a situações particulares dentro do grupo. Permite-se nessa via a solução de parcela da controvérsia - remetendose à análise de questões particulares para outros momentos e distintos processos - autoriza-se a adequação do procedimento às peculiaridades de cada caso e, enfim, confere poderes de gestão bastante abertos para o juiz que tratará do caso (a regulamentação prevê a nomeação de um juiz - "managing judge" - para tratar do caso submetido à GLO). De fato, esse magistrado possui amplos poderes para administrar o tratamento do caso da forma mais justa e eficiente possível, podendo variar a tramitação procedimental conforme as circunstâncias
} 
Revista Eletrônica de Direito Processual - REDP.

Rio de Janeiro. Ano 13. Volume 20. Número 2. Maio a Agosto de 2019

Periódico Quadrimestral da Pós-Graduação Stricto Sensu em Direito Processual da UERJ

Patrono: José Carlos Barbosa Moreira (in mem.). ISSN 1982-7636. pp. 245-266 www.redp.uerj.br

Esse pano de fundo também é basal à lógica de multidistrict litigation, que dá fundo ao atual ensaio. De uma forma geral, a técnica, regulamentada em 1968 (28 USC, §1407), prevê que "quando demandas civis envolvendo uma ou mais questões comuns de fato ou de direito estejam pendentes de julgamento em distintos distritos, elas sejam transferidas para qualquer um deles para consolidação ou coordenação dos procedimentos de pre-trial" ${ }^{24}$. Sua incidência estaria adstrita à esfera federal, podendo, nesse campo, ser impulsionada tanto por alguma das partes quanto pelo Judicial Panel on Multidistrict Litigation - órgão elementar para o seu funcionamento.

Diante disso, constata-se com Tidmarsh que, em sua leitura original, a técnica possuía como vocação a tentativa de agregar medidas individuais para finalidades especificamente afetas à produção probatória ${ }^{25}$. Seria essa a sua atribuição essencial. Vejase, ainda, que a ideia de mostrava bastante inovadora no contexto de aprovação do texto legislativo - anunciando-se como uma peça inédita no quebra-cabeça processual ${ }^{26}$.

Levando-se em conta esse objetivo inicial, há diferentes situações que poderiam encorajar o uso da técnica. Pense-se, por exemplo, em circunstâncias nas quais se efetivam danos ambientais de larga escala, como aquelas recentemente vivenciadas por nossa sociedade nos municípios de Mariana/MG e de Brumadinho/MG. Nesses casos, além do evidente dano metaindividual, há diferentes prejuízos estritamente individuais merecedores de reparação. E, potencialmente, permitir a produção coletiva da prova de um elemento

\footnotetext{
peculiares de cada caso, ou mesmo das situações individuais reunidas para análise conjunta”. ARENHART, Sérgio Cruz. OSNA, Gustavo. Ob. cit. p. 373-374.

24 "(a)When civil actions involving one or more common questions of fact are pending in different districts, such actions may be transferred to any district for coordinated or consolidated pretrial proceedings. Such transfers shall be made by the judicial panel on multidistrict litigation authorized by this section upon its determination that transfers for such proceedings will be for the convenience of parties and witnesses and will promote the just and efficient conduct of such actions. Each action so transferred shall be remanded by the panel at or before the conclusion of such pretrial proceedings to the district from which it was transferred unless it shall have been previously terminated: Provided, however, That the panel may separate any claim, cross-claim, counter-claim, or third-party claim and remand any of such claims before the remainder of the action is remanded".

25 "The original concept underpinning the MDL statute was to provide a mechanism to coordinate discoverythrough such means as common discovery orders, national depositions conducted for use in individual cases on remand, and centralized document depositories". TIDMARSH, Jay. The MDL as De Facto Opt In Class Action. Disponível em <https://www.law.gwu.edu/sites/g/files/zaxdzs2351/f/downloads/Tidmarsh-MDLPaper.pdf $>$. Acesso em 10 de janeiro de 2019.

${ }^{26}$ Ver, BRADT, Andrew. The Long Arm of Multidistrict Litigation. In. William \& Mary Law Review. v.59. Williamsburg: William \& Mary Law School, 2018. p.1199 e ss.
} 
Revista Eletrônica de Direito Processual - REDP.

Rio de Janeiro. Ano 13. Volume 20. Número 2. Maio a Agosto de 2019

Periódico Quadrimestral da Pós-Graduação Stricto Sensu em Direito Processual da UERJ

Patrono: José Carlos Barbosa Moreira (in mem.). ISSN 1982-7636. pp. 245-266

www.redp.uerj.br

comum a esses aspectos (como o nexo de causalidade entre a atuação de determinada empresa e o abalo) poderia representar um caminho benéfico à prestação jurisdicional ${ }^{27}$.

Além desse aspecto, seria possível também pensar, como realizado por Thaís Lunardi, em circunstâncias nas quais a coletivização da prova poderia ser pertinente a partir do curso paralelo de medidas tipicamente individuais. O exemplo dado pela autora é o do notório caso das pílulas de farinha, havido no Brasil pouco mais de duas décadas atrás. Nessa circunstância, a produção coletivizada da prova também teria aptidão para facilitar a posterior apreciação das pretensões iniciais ${ }^{28}$.

Enfim, partindo desse pano de fundo, nota-se o porquê de se ter estabelecido textualmente que a multidistrict litigation estaria adstrita às fases de trial e de pre-trial. É que, tratando-se de meio ligado à formação coletiva da prova, seria precisamente esse o seu campo de atuação. Mais que isso, contata-se, por qual motivo o legislador optou por atribuir ao mecanismo um regime procedimental bastante flexível. Trata-se de caminho necessário para compatibilizar o uso da técnica com as diferentes circunstâncias materiais que poderiam justifica-la.

\section{A Técnica de Multidistrict Litigation: Real Solução?}

Se nas páginas acima se procurou desenhar um cenário geral ligado às funções e à expansão do multidistrict litigation, os tópicos subsequentes se valem desse arsenal argumentativo para oferecer resposta à pergunta central do ensaio (isso é, ao fato de essa técnica servir como uma efetiva alternativa às ações de classe). Com esse escopo, investigase, inicialmente, a caracterização desse instrumento como um mecanismo de coletivização parcial de direitos - situando sua posição formal no tabuleiro da tutela coletiva. Na sequência, porém, é exposto um elemento inerente à atual concretização da ferramenta que pode levar a uma possível divergência entre o seu discurso e a sua prática.

\footnotetext{
${ }^{27}$ Assim, LUNARDI, Thais Amoroso Paschoal. Coletivização da Prova: Técnicas de produção coletiva da prova e seus reflexos na esfera individual. Tese de Doutorado. Universidade Federal do Paraná - UFPR, 2018. ${ }^{28}$ Idem.
} 
Revista Eletrônica de Direito Processual - REDP.

Rio de Janeiro. Ano 13. Volume 20. Número 2. Maio a Agosto de 2019

Periódico Quadrimestral da Pós-Graduação Stricto Sensu em Direito Processual da UERJ

Patrono: José Carlos Barbosa Moreira (in mem.). ISSN 1982-7636. pp. 245-266

www.redp.uerj.br

\subsection{A Multidistrict e a Coletivização Parcial}

Conforme sinalizado no capítulo anterior, a técnica de multidistrict litigation não é recente no ordenamento estadunidense. Contudo, o avanço do seu uso ao longo dos últimos anos é notório. Numericamente, estima-se que cerca de $40 \%$ (quarenta) por cento das disputas atualmente em tramite na esfera federal tenham em algum momento sido afetadas pela instauração do mecanismo - o que, logicamente, demonstra a importância no seu uso 29.

Seria a ferramenta em questão, então, uma real alternativa ao modelo de ação de classe? Seu avanço realmente condiz com as finalidades inicialmente pensadas para o instituto? De que forma o mecanismo tem se efetivado na realidade estadunidense?

Para compreender as indagações, é importante lembrar que, como posto, as class actions sofreram diferentes críticas ao longo de sua evolução histórica - focadas, especialmente, no fato de limitarem direitos individuais e vincularem sujeitos que não participaram da disputa (absent parties). E, de uma forma geral, pode-se dizer que a multidistrict litigation - a partir de sua natureza flexível - ao menos aparentemente driblaria esses imbróglios. Foi precisamente por força disso que, em meio às críticas às ações de classe, ela se fortaleceu ${ }^{30}$.

Realmente, considerando que em uma primeira análise a técnica em questão atingiria apenas etapas inerentes à produção probatória, evidentemente sua assertividade não se compararia àquela das ações de classe. Da mesma forma, tratando-se de mecanismo de coletivização parcial, seu efeito mais imediato não tocaria sujeitos que não houvessem ingressado na esfera jurisdicional.

Esmiuçando esse ponto, vale lembrar que, como visto, a tutela coletiva se construiu em diferentes localidades de maneira total ou parcial. No primeiro campo,

\footnotetext{
29 "If there is one thing every first-year law student knows a lot about, it is personal jurisdiction-a staple of every introductory Civil Procedure course. But any $1 \mathrm{Ls}$ who have survived the journey from Pennoyer to International Shoe to the Supreme Court's recent flurry of jurisdiction cases might be surprised to learn that in nearly 40 percent of the cases on the federal civil docket, much of what they learned is practically irrelevant. That is because those cases-as of August 2017, some 125,000 of them-are consolidated as part of a multidistrict litigation, or MDL". BRADT, Andrew. Ob. cit. p.1168.

30 "MDL, once thought to be an obscure, technical device, has now become the centerpiece of nationwide mass tort litigation in the wake of the decline of the tort class action. Under the MDL statute,28 U.S.C. $\$ 1407$, thousands of cases pending around the country that share a common question of fact can be transferred to a single district judge in any district for pretrial proceedings". Idem. p.1168-1169.
} 
Revista Eletrônica de Direito Processual - REDP.

Rio de Janeiro. Ano 13. Volume 20. Número 2. Maio a Agosto de 2019

Periódico Quadrimestral da Pós-Graduação Stricto Sensu em Direito Processual da UERJ

Patrono: José Carlos Barbosa Moreira (in mem.). ISSN 1982-7636. pp. 245-266

www.redp.uerj.br

compatível com a ação de classe, haveria aptidão para proteger sujeitos que não atuaram

pessoalmente em juízo. A questão seria uma virtude para tópicos como o acesso à justiça, superando entraves inerentes àquilo que Cappelletti e Garth denominaram de capacidade jurídica pessoal ${ }^{31}$. Não obstante, sua concretização passaria inevitavelmente pelo sacrifício antes mencionado: para proteger sujeitos que não participaram da disputa, seria também preciso que eles, mesmo ausentes, fossem atingidos pela decisão coletiva.

Já no bojo das técnicas de coletivização parcial esse tipo de diálogo costuma ocorrer de maneira menos direta e radical. De forma breve, é padrão que nesse tipo de mecanismo o ato coletivo vincule, apenas, aqueles sujeitos que impulsionaram individualmente a máquina judiciária. Assim, a eventual garantia individual de ação, em maior ou em menor escala, seguiria sendo observada ${ }^{32}$.

Quais seriam, porém, as demais vantagens ou desvantagens inerentes a essa via? Em que sentido, funcionalmente, os mecanismos seriam diversos? Essa discrepância teleológica efetivamente existiria?

Em relação à última das indagações, umbilicalmente ligada às demais, não temos dúvidas de que a resposta é positiva. Tratando-se de técnicas diversas, sua fundamentação funcional é igualmente discrepante, fazendo com que sustentar a adoção de uma ou de outra seja - antes de tudo - indagar o que se quer com a agregação.

Nesse jogo, porém, é evidente que as ações de classe possuirão um peso mais efetivo em aspectos como a gestão da estrutura judiciária - resolvendo em um único processo aspectos que poderiam ensejar milhares de medidas ${ }^{33}$. Da mesma forma, também é nítido

\footnotetext{
${ }^{31}$ Trata-se das "inúmeras barreiras que precisam ser pessoalmente superadas, antes que um direito possa ser efetivamente reivindicado através de nosso aparelho judiciário". Esclarecendo, afirmam que "num primeiro nível está a questão de reconhecer a existência de um direito juridicamente exigível. Essa barreira fundamental é especialmente séria para os despossuídos, mas não afeta apenas os pobres. Ela diz respeito a toda a população em muitos tipos de conflitos que envolvem direitos (...) mesmo consumidores bem informados, por exemplo, só raramente se dão conta de que sua assinatura num contrato não significa que precisem, obrigatoriamente, sujeitar-se a seus termos, em quaisquer circunstâncias. Falta-lhes o conhecimento jurídico básico não apenas para fazer objeção a esses contratos, mas até mesmo para perceber que sejam passíveis de objeção". CAPPELLETTI, Mauro. GARTH, Bryant. Acesso à justiça. Trad. Ellen Gracie Northfleet. Porto Alegre: Editora Sérgio Fabris, 1988. p. 22-23.

${ }^{32}$ Colocando as duas figuras lado a lado, ERICHSON, Howard M. What MDL and Class Actions Have in Common. In. Vanderbilt Law Review. v.70. Nashville: Vanderbilt Law School, 2017.

${ }^{33}$ No mesmo sentido, BONE, Robert G. Civil Procedure - The Economics of Civil Procedure. New York: Foundation Press, 2003. p.202. Também Gidi, afirmando que "o objetivo mais imediato das ações coletivas é o de proporcionar eficiência e economia processual, ao permitir que uma multiplicidade de ações individuais repetitivas em tutela de uma mesma controvérsia seja substituída por uma única ação coletiva (...) a possibilidade de julgar em um único processo uma controvérsia complexa envolvendo inúmeras pessoas, por outro lado, representa uma notável economia para o Judiciário.” GIDI, Antonio. Ob. cit. p.26
} 
Revista Eletrônica de Direito Processual - REDP.

Rio de Janeiro. Ano 13. Volume 20. Número 2. Maio a Agosto de 2019

Periódico Quadrimestral da Pós-Graduação Stricto Sensu em Direito Processual da UERJ

Patrono: José Carlos Barbosa Moreira (in mem.). ISSN 1982-7636. pp. 245-266

www.redp.uerj.br

que esse ponto tenderia a contribuir de forma mais firme para a efetivação do acesso à justiça

- por proteger toda a classe, superando barreiras ou desestímulos precedentes ao ingresso em juízo. Ainda, a técnica exerceria maior autoridade no que toca à isonomia processual.

Afinal, ao vincular todo o grupo a uma única decisão, é obvio que os interessados também receberiam uma mesma decisão.

Por outro lado, cada um desses pontos decorre do próprio fato de, ao falar-se em coletivização parcial de direitos, não se evitar que seja trazida para o jogo do processo algum grau de dispersão; de fracionamento das pretensões individuais. Como consequência, os perigos, os riscos e as desvantagens decorrentes dessa pulverização voltam a existir inibindo-se ou reduzindo-se a sua verificação, apenas, em determinado aspecto pontual.

Compreendendo a questão, pensemos em uma situação hipotética que, em princípio, poderia impulsionar o uso tanto de uma técnica como a class action quanto de um mecanismo análogo ao multidistrict litigation: após verificação de grave abalo ambiental em uma baía, próximo a polo industrial petrolífero ali situado, constata-se a existência de diferentes prejuízos individuais a comunidades localizadas na região. Mais que isso, cogitase haver responsabilidade direta da sociedade empresária pelo ocorrido, tornando-a ré em potencial das diferentes pretensões relacionadas ao caso.

Nesse caso, por meio de uma técnica de ação de classe, seria possível que todos os sujeitos individualmente lesados pelo ato fossem protegidos dentro de um mesmo processo. Adicionalmente, por meio de um sistema executivo dinâmico - como oportunizado pelas US Class Actions ${ }^{34}$-, essa tutela poderia bater em sua porta sem que jamais tivessem adotado qualquer impulso individual para tanto. Analisando os benefícios acima indicados: (i) o ganho de isonomia seria flagrante, já que a resposta atribuída a todos os integrantes da classe seria a mesma, proferida na lide coletiva; (ii) o incremento do acesso à justiça também seria nítido, tendo em conta que, ao proteger os sujeitos sem a necessidade de impulso individual, conferir-se-ia amparo àqueles que não disporiam de estímulo ou de condição de ingressar isoladamente em juízo; e (iii) em relação à gestão da justiça, o benefício também seria inequívoco - já que, ao invés de diferentes ações individuais ligadas ao mesmo tema, os esforços seriam concentrados e consolidados em um único feito.

\footnotetext{
${ }^{34}$ A respeito da execução da decisão coletiva, ver, ARENHART, Sérgio Cruz. OSNA, Gustavo. Ob. cit. p. 318 e ss.
} 
Revista Eletrônica de Direito Processual - REDP.

Rio de Janeiro. Ano 13. Volume 20. Número 2. Maio a Agosto de 2019

Periódico Quadrimestral da Pós-Graduação Stricto Sensu em Direito Processual da UERJ

Patrono: José Carlos Barbosa Moreira (in mem.). ISSN 1982-7636. pp. 245-266

www.redp.uerj.br

Por outro lado, também é certo que o exemplo mencionado poderia servir como campo para o emprego de um mecanismo de coletivização parcial, como o multidistrict litigation. Tomando como base especificamente essa técnica, seria razoável que, diante dos diferentes debates decorrentes do dano ambiental, realizasse-se a produção coletiva de prova pericial ligada à participação da empresa petrolífera no abalo. Procedimentalmente, então, o cenário assumiria os seguintes contornos: (i) verificados diferentes debates em juízo ligados à matéria de fundo em questão, seria suscitado incidentalmente o multidistrict, com o propósito de produzir conjuntamente determinada prova pericial ou testemunhal ligada ao abalo; (ii) a produção probatória, então, ocorreria perante o Panel, a quem também incumbiria a atribuição de nomear, entre advogados qualificados para tanto, o representante da classe ${ }^{35}$; e (iii) enfim, após produzida a prova, as medidas individuais retomariam sua tramitação original, podendo se valer de tal acervo probatório.

Diante desse procedimento, então, percebe-se que há uma evidente timidez no que toca aos benefícios que o mecanismo poderia alcançar. Aqui: (i) o ganho à isonomia seria relativo, já que, após a produção de prova, ocorreria uma nova dispersão dos processos. Assim, considerando que o Panel não julgaria o caso, mas apenas facilitaria sua instrução, seria possível que diferentes juízes atingissem conclusões diversas a respeito do material probatório; (ii) em relação ao acesso à justiça, por sua vez, o ganho alcançado pela class action sequer seria aqui perseguido. Como é intuitivo, a prova beneficiaria apenas os sujeitos que efetivamente viessem a ingressar em juízo - salvo na hipótese de eventual propositura de ação coletiva. Para os demais, ela de nada serviria; (iii) por último no que toca ao ganho ocasionado para a administração da justiça, também haveria uma vantagem (apenas) relativa. Embora não se chegasse à redução de processos alcançada pela ação coletiva, ao menos os esforços ligados à produção probatória seriam centralizados - evitando-se a reiteração desse ponto.

Por outro lado, precisamente por não vincular quem não ingressasse em juízo e por teoricamente permitir o desligamento de quem assim pleiteasse - as críticas trazidas à class action também seriam em larga medida esquivadas pelo mecanismo em questão. É que, em linhas gerais, a submissão ao Panel seria provida de certo grau de voluntariedade, o que

\footnotetext{
${ }^{35}$ Problematizando essa questão, ver BURCH, Elizabeth Chamblee. Repeat Players in Multidistrict Litigation: The Social Network. In. Cornell Law Review. v. 102. Ithaca: Cornell Law School, 2017.
} 
Revista Eletrônica de Direito Processual - REDP.

Rio de Janeiro. Ano 13. Volume 20. Número 2. Maio a Agosto de 2019

Periódico Quadrimestral da Pós-Graduação Stricto Sensu em Direito Processual da UERJ

Patrono: José Carlos Barbosa Moreira (in mem.). ISSN 1982-7636. pp. 245-266

www.redp.uerj.br

permitiria que o uso da técnica se valesse de um horizonte azul e passasse ao lado de restrições teóricas mais contundentes.

\subsection{O Drible da Multidistrict: Quasi-Class Action e Pulverização}

Considerando o aspecto posto no item anterior, seria visível que o mecanismo da multidistrict possui atuação muito menos radical do que as ações de classe - evitando, por isso, boa parte das ressalvas contra elas direcionadas. Contudo, no mesmo passo, também se tornaria bastante claro que os benefícios a serem ocasionados pelo mecanismo seriam limitados. Ao se coletivizar apenas a produção probatória inerente à disputa, os riscos da pulverização estariam presentes e poderiam atuar em sentido contrário à efetividade jurisdicional.

Não obstante, é precisamente aqui que o instrumento em questão parece vir driblando as suas próprias finalidades originais ${ }^{36}$. Valendo-se de seu regime normativo propositadamente aberto, o multidistrict litigation tem cada vez menos servido como um meio efetivamente voltado à produção coletiva da prova - convertendo-se, em verdade, em uma ferramenta para a resolução coletiva de questões individuais. Torna-se então, para alguns, uma quasi-class action ${ }^{37}$.

Procurando elucidar o problema, lembremos novamente a eventual aplicação da transferência do multidistrict ao exemplo previamente trazido no presente artigo, relacionado a uma indústria petrolífera potencialmente ligada a um abalo ambiental. Nesse caso, vimos que a aplicabilidade do mecanismo em questão poderia gerar uma espécie de incidente de coletivização da prova. Perante o Panel, então, realizar-se-ia conjuntamente a produção probatória ligada a um ou mais aspectos em comum, como o nexo de causalidade entre o dano e as atividades da empresa. Na sequência, porém, as medidas retomariam seu curso de forma pulverizada.

\footnotetext{
${ }^{36}$ Assim, TIDMARSH, Jay. Ob. cit.

${ }^{37}$ Ver, expondo a aproximação, ISSACHAROFF, Samuel. Private Claims, Aggregate Rights. In. The Supreme Court Review. Chicago: The University of Chicago Press, 2008. Perceba-se que a questão não é vista sem olhares críticos. Assim, MUELLENIX, Linda S. Aggregate Litigation And The Death Of Democratic Dispute Resolution. In. Northwestern University Law Review. v.105. Chicago: Nortwestern School of Law, 2013. p.52 e ss.
} 
Revista Eletrônica de Direito Processual - REDP.

Rio de Janeiro. Ano 13. Volume 20. Número 2. Maio a Agosto de 2019

Periódico Quadrimestral da Pós-Graduação Stricto Sensu em Direito Processual da UERJ

Patrono: José Carlos Barbosa Moreira (in mem.). ISSN 1982-7636. pp. 245-266

www.redp.uerj.br

Como visto, esse cenário traria diferentes áleas para o processo, revelando uma

efetividade reduzida. Além de inexistir um ganho sensível à administração da justiça, sequer a isonomia seria verdadeiramente preservada. Isso porque, diante de uma mesma prova, nada garantiria que diferentes magistrados atingiriam uma mesma conclusão. A cisão entre produção e valoração da prova, como consequência, assumiria papel central.

Ocorre que, materialmente, o mecanismo de multidistrict litigation vem possuindo uma aplicabilidade que não coincide com a do seu desenho teórico. Embora a ideia original do mecanismo pressupusesse esse retorno ao juízo originário após a produção da prova coletiva, a realidade demonstra que essa retomada da tramitação originária não costuma ocorrer. Na realidade, menos de três por cento dos processos submetidos ao multidistrict realizam esse trajeto ${ }^{38}$. Nas demais hipóteses, acaba-se chegando a alguma forma de acordo coletivo - de tal modo que a fase de pre-trial passa a responder por toda a tramitação do processo ${ }^{39}$.

Tomando como base o exemplo previamente referido, então, a realidade do multidistrict é que os processos ligados ao dano ambiental, após a instauração do incidente coletivo, jamais voltassem a tramitar isoladamente. Pelo contrário, por meio de uma autocomposição coletiva, a questão tenderia a ser acertada coletivamente. Como consequência, não é exagerado afirmar que a técnica se apresenta como uma ferramenta de coletivização parcial - esquivando-se, com isso, das críticas comuns às ações de classe -, mas, concretamente, atua como uma figura de coletivização total.

Revela-se, nessa medida, que a real intenção do instrumento, contemporaneamente, não é coletivizar a prova, mas resolver a própria questão coletiva. Conforme Tidmarsh, ele se aproxima, e muito, de uma verdadeira class action marcada pelo exercício de opt in (que, no caso, coincidiria com a propositura da ação) ${ }^{40}$.

\footnotetext{
38 "After such pretrial proceedings, the cases are to be remanded to the courts from which they came for trial, but this rarely happens - less than 3 percent of the cases ever exit the MDL court Instead, most of the cases are either settled or resolved in the MDL proceeding, meaning that, as in most federal litigation, pretrial proceedings are the whole ballgame”. BRADT, Andrew. Ob. cit. p.1169.

${ }^{39}$ Ver, NAGAREDA, Richard. 1938 All Over Again? Pre-Trial as Trial in Complex Litigation. In. DePaul Law Review. v.60. Chicago: DePaul University College of Law, 2011.

40 "In short, the realities and practicalities of the modern MDL diminish the effective differences between an $M D L$ process and an opt-in class action. Of course, opt-in class actions have one remaining, and highly critical, difference from the MDL process. Opt-in class actions traditionally rely on the consent of the members of the class to join together. With the MDL, the consent is more attenuated: the plaintiffs at best consent to bring their cases in federal court, aware (assuming knowledge of the law) of the powers of the Panel to consolidate their cases with other like cases. They need not, however, consent to the consolidation in the MDL process itself. The responsibility for construction of the class is instead undertaken by the Judicial Panel-an
} 
Revista Eletrônica de Direito Processual - REDP.

Rio de Janeiro. Ano 13. Volume 20. Número 2. Maio a Agosto de 2019

Periódico Quadrimestral da Pós-Graduação Stricto Sensu em Direito Processual da UERJ

Patrono: José Carlos Barbosa Moreira (in mem.). ISSN 1982-7636. pp. 245-266

www.redp.uerj.br

Nesses termos, não surpreende ainda que as mesmas críticas trazidas às class

actions também tenham passado a endereçar o uso do multidistrict. Em síntese, se a técnica teoricamente não limitaria o exercício de garantias individuais, seu uso faz com que esse conflito volte a haver. Além disso, diante da flexibilidade do mecanismo, sequer as mesmas salvaguardas formais existentes nas class actions estariam presentes, gerando inúmeras dúvidas.

Afinal, no âmbito do mecanismo de coletivização, em quais hipóteses poderia o Panel deixar de homologar eventual acordo? Que tipo de critério poderia ou não ser adotado nessa análise, dado o silêncio legislativo ligado ao tema? Na mesma linha, o órgão possuiria reais poderes para proceder a essa avaliação?

Cada uma das questões tem sido levantada em esfera doutrinária, suscitando reflexões sobre a legitimidade do mecanismo e sobre uma eventual necessidade de retorno às suas funções originais. Autores como Martin Redish e Julie Karaba, por exemplo, retomam a crítica já direcionada às ações de classe - colocando em dúvida a adequação constitucional do multidistrict, em sua atual feição ${ }^{41}$. Por essa razão, ao se cogitar o uso de figuras análogas no Brasil, é preciso estar ciente desse pano de fundo e colocar todas as cartas na mesa.

\section{Considerações Finais}

Se em nossa realidade tem sido gradualmente conferida maior atenção à técnica de multidistrict litigation, reconhecendo-a como possível alternativa ao regime de ações de classe, o presente artigo procurou colocar um ponto de maior ceticismo ligado à questão. $\mathrm{E}$ isso porque, como visto, o avanço material desse mecanismo parece se dever especialmente ao fato de ele, em que pese possuir estrutura teórica ligada à ideia de coletivização parcial de direitos, atuar como um mecanismo de coletivização total. Se o seu uso se destinaria apenas à produção coletiva da prova, o que se vê é que, materialmente, o mecanismo se

undertaking that can occur either at the request of any party or on its own initiative". TIDMARSH, Jay. Ob. cit.

${ }^{41}$ Assim, passim, REDISH, Martin H. KARABA, Julie M. One size doesn't fit all: multidistrict ligitation, due peocess, and the dangers of procedural collectivism. In. Boston University Law Review. v.95. Boston: Boston University School of Law, 2015. 
Revista Eletrônica de Direito Processual - REDP.

Rio de Janeiro. Ano 13. Volume 20. Número 2. Maio a Agosto de 2019

Periódico Quadrimestral da Pós-Graduação Stricto Sensu em Direito Processual da UERJ

Patrono: José Carlos Barbosa Moreira (in mem.). ISSN 1982-7636. pp. 245-266

www.redp.uerj.br

presta à própria pacificação das disputas. Por essa razão, a sua legitimidade tem sido gradativamente vista com maiores ressalvas.

Concluindo o estudo, porém, cabe formular algumas indagações finais: por qual motivo essa expansão ocorreu? O que fez com que esse avanço tivesse lugar, alterando o próprio sentido da técnica?

É precisamente nesse ponto que, em nossa visão, reside o principal gargalo para compreensão da tutela coletiva. É que, conforme previamente sinalizado, os benefícios trazidos por qualquer via de coletivização parcial são inevitavelmente limitados. Como consequência, sua adoção pode representar uma opção, apenas, se a pretensão de melhoria sistêmica também for tímida ${ }^{42}$. Caso contrário, o caminho não parece suficiente.

Por força disso, considera-se que a única saída salutar para adoção de um modelo verdadeiramente efetivo de processo coletivo é o reconhecimento franco de que sua aplicação, de fato, exigirá uma releitura das garantias do processo; imporá uma redução do módulo de participação individual, casuisticamente justificada e suprida por uma adequada representação. Somente dessa forma os benefícios inerentes à tutela coletiva podem ser potencializados em toda sua extensão. Caso contrário, seguirão havendo chances perdidas, ou dribles que não tardarão a ser objeto de desarme.

\footnotetext{
${ }^{42}$ Veja-se, assim, Walter afirmando que a não-adoção de modelos de ação de classe por alguns países europeus se deve, exatamente, ao fato de não perseguirem em sua totalidade os benefícios almejados pela class action. Nas palavras do autor, "Class actions do not exist in Germany, Switzerland, and most other countries of the civil law system. The simple rule is that, in general, everyone. has standing for an action only regarding his or her own claim. Intermediate or representative actions for other persons do not exist. Mass torts occur in Germany and Switzerland as well as in other countries. German and Swiss courts have found ways to deal with them in an adequate way. Although the instrument of a class action is not known in Germany and Switzerland, Swiss courts have developed other procedural means to deal with mass torts. Moreover, due to the dependence of Germany and Switzerland on international trade and commerce, their courts and lawyers have considerable experience in dealing with complex international litigation. So, then, how do we deal with mass tort cases? First, many issues that would give rise to a class action in the United States as a civil case are dealt with by government agencies. For example, in Switzerland there is a Federal Office for the Equal Treatment of Men and Women to deal with issues of sexual discrimination, and the Federal Cartel Commission is charged with enforcing antitrust legislation. Second, model suits, funds solutions, and public-interest organization's actions (Verbandsklagen), and several multiparty solutions, all of which I will return to in a moment, are available to deal with mass torts". WALTER, Gerhard. Mass Tort Litigation in Germany and Switzerland. In. Duke Journal of Comparative \& International Law. v.11. Durham: Duke University, 2001. p.372-373.
} 
Revista Eletrônica de Direito Processual - REDP.

Rio de Janeiro. Ano 13. Volume 20. Número 2. Maio a Agosto de 2019

Periódico Quadrimestral da Pós-Graduação Stricto Sensu em Direito Processual da UERJ

Patrono: José Carlos Barbosa Moreira (in mem.). ISSN 1982-7636. pp. 245-266

www.redp.uerj.br

\section{REFERÊNCIAS}

ANDREWS, Neil. O Moderno Processo Civil. Trad. Teresa Arruda Alvim Wambier. São Paulo: Ed. RT, 2009.

ARENHART, Sérgio Cruz. OSNA, Gustavo. Curso de Processo Civil Coletivo. São Paulo:

Ed. RT, 2019.

BONE, Robert G. Civil Procedure - The Economics of Civil Procedure. New York: Foundation Press, 2003.

BRADT, Andrew. The Long Arm of Multidistrict Litigation. In. William \& Mary Law Review. v.59. Williamsburg: William \& Mary Law School, 2018.

BURCH, Elizabeth Chamblee. Repeat Players in Multidistrict Litigation: The Social Network. In. Cornell Law Review. v. 102. Ithaca: Cornell Law School, 2017.

CABRAL, Antonio do Passo. O novo procedimento-modelo (Musterverfahren) alemão: uma alternativa às ações coletivas. In. Revista de Processo. v.147. São Paulo: Ed.RT, 2007.

CAPPELLETTI, Mauro. GARTH, Bryant. Acesso à justiça. Trad. Ellen Gracie Northfleet. Porto Alegre: Editora Sérgio Fabris, 1988.

CRUZ E TUCCI, José Rogério. Class action e mandado de segurança coletivo, diversificações conceptuais. São Paulo: Ed. RT, 1990.

ERICHSON, Howard M. What MDL and Class Actions Have in Common. In. Vanderbilt Law Review. v.70. Nashville: Vanderbilt Law School, 2017.

GIDI, Antonio. A Class Action como instrumento de tutela coletiva de direitos. São Paulo: Ed. RT, 2007.

HENSLER, Deborah. Class Action Dilemmas - Pursuing public goals for private gain. Santa Monica: Rand, 2000.

ISSACHAROFF, Samuel. Civil Procedure. New York: Foundation Press, 2005.

ISSACHAROFF, Samuel. Private Claims, Aggregate Rights. In. The Supreme Court Review. Chicago: The University of Chicago Press, 2008.

LAHAV, Alexandra D. Two Views of Class Action. In. Fordham Law Review. n.79. New York: Fordham University, 2011. 
Revista Eletrônica de Direito Processual - REDP.

Rio de Janeiro. Ano 13. Volume 20. Número 2. Maio a Agosto de 2019

Periódico Quadrimestral da Pós-Graduação Stricto Sensu em Direito Processual da UERJ

Patrono: José Carlos Barbosa Moreira (in mem.). ISSN 1982-7636. pp. 245-266 www.redp.uerj.br

LUNARDI, Thais Amoroso Paschoal. Coletivização da Prova: Técnicas de produção coletiva da prova e seus reflexos na esfera individual. Tese de Doutorado. Universidade Federal do Paraná - UFPR, 2018.

MENDES, Aluisio Gonçalves de Castro. Ações coletivas no direito comparado e nacional.

2. ed. São Paulo: Ed. RT, 2009.

MUELLENIX, Linda S. Aggregate Litigation And The Death Of Democratic Dispute Resolution. In. Northwestern University Law Review. v.105. Chicago: Nortwestern School of Law, 2013.

NAGAREDA, Richard. 1938 All Over Again? Pre-Trial as Trial in Complex Litigation. In. DePaul Law Review. v.60. Chicago: DePaul University College of Law, 2011.

OSNA, Gustavo. Direitos individuais homogêneos: pressupostos, fundamentos $e$ aplicação no processo civil. São Paulo: Ed. RT, 2014.

REDISH, Martin. Wholesale Justice - Constitutional Democracy and the Problem of the Class Action Lawsuit. Stanford: Stanford University Press, 2009.

REDISH, Martin H. KARABA, Julie M. One size doesn't fit all: multidistrict litigation, due peocess, and the dangers of procedural collectivism. In. Boston University Law Review. v.95. Boston: Boston University School of Law, 2015.

ROQUE, André Vasconcelos. Class Action - Ações Coletivas nos Estados Unidos: o que podemos aprender com eles? Salvador: Editora JusPodivm, 2013.

SHAPIRO, David L. Class Actions: The Class as Party and Client. In. Notre Dame Law Review. vol.73. Notre Dame: University of Notre Dame, 1998.

TIDMARSH, Jay. The MDL as De Facto Opt In Class Action. Disponível em <https://www.law.gwu.edu/sites/g/files/zaxdzs2351/f/downloads/Tidmarsh-MDLPaper.pdf>. Acesso em 10 de janeiro de 2019.

VITORELLI, Edilson. O devido processo legal coletivo: dos direitos aos litígios coletivos. São Paulo: Ed. RT, 2016.

WALTER, Gerhard. Mass Tort Litigation in Germany and Switzerland. In. Duke Journal of Comparative \& International Law. v.11. Durham: Duke University, 2001. 